\title{
Cystic fibrosis: physical exercise versus chest physiotherapy
}

\author{
M ZACH, B OBERWALDNER, AND F HÄUSLER \\ University Children's Hospital, Graz, and Paediatric Department, Stolzalpe, Austria
}

SUMmaRY Twelve children with cystic fibrosis were admitted to a paediatric rehabilitation hospital for 17 days to take part in a training programme of vigorous physical excercise and sport. The daily inhalation-physiotherapy routine was stopped. Ventilatory status was assessed by spirometry and measurement of lung volumes one day before admission, one day after the end of the hospital stay, and 8 weeks later. Flow measurements of forced expiration had improved appreciably by the end of the course, but most of them returned to pretraining levels 8 weeks later. Lung volumes did not change significantly. Daily recordings of peak flow indicated improvement of airways function plus some ventilatory muscle training. Regular physical exercise could replace the inhalation-physiotherapy routine in some children with cystic fibrosis.

Aerosol inhalation followed by chest physiotherapy is an essential part of the life-long therapeutic routine in cystic fibrosis (CF). Patient compliance however, is often poor, especially in older children. The efficacy of these procedures to mobilise and remove secretions seems to decrease with age. A more effective and popular alternative is needed.

Swimming in conjunction with the inhalationphysiotherapy routine has been shown to increase sputum production and to improve ventilatory function. ${ }^{1}$ This stimulated us to study the changes in pulmonary function after inhalation and chest physiotherapy had been replaced by a short programme of intense physical exercise and sport.

\section{Patients and methods}

Six boys and 6 girls, with a median age of $10 \frac{1}{2}$ years (range $24 / 12$ to $163 / 12$ ) and a median clinical Shwachman score ${ }^{2}$ of 69 (range 37 to 86 ) were sent to a paediatric rehabilitation hospital situated in a mountainous area in upper Styria (altitude $1180 \mathrm{~m}$ above sea level). They were chosen from children attending the CF clinic at the University Children's Hospital, Graz, on the basis of repeatedly positive sweat tests, ${ }^{3}$ a stable clinical condition, and willingness to participate.

The routine therapeutic regimen of these children had included pancreatic enzyme replacement and appropriate diet. Chest physiotherapy administered by either a parent or the patient had followed aerosol inhalation twice daily. In addition 5 children were on oral antibiotics. None used bronchodilators. Five children had taken part in a previous study. ${ }^{1}$ Two months before admission parents and children were instructed to keep strictly to the inhalationphysiotherapy routine.

In order to reduce any seasonal or occupational influences on clinical condition or pulmonary function, the study was conducted in the summer holidays. The hospital stay lasted 17 days and during this time aerosol inhalation and chest physiotherapy were stopped. The rest of the therapeutic routine was maintained. All children participated in an intensive programme of physical exercise and sport led by a chest physiotherapist (B O), experienced in $\mathrm{CF}$ care and familiar with the patients. Activities included one hour of swimming and diving twice a day. As the teaching pool was some $2 \frac{1}{2} \mathrm{~km}$ from the paediatric department, the children jogged from one to the other. The children hiked for several hours through the surrounding forests and mountains, collecting firewood, berries, and mushrooms. In addition all children took part in gymnastics, skipping, and according to their inclination, in minigolf, soccer, and table tennis. The remaining time was occupied by group games, camp-fire activities with barbecue meals, singing, chatting, and storytelling.

After the end of the course the children returned to their homes and resumed their pre-course inhalation-physiotherapy routine.

Ventilatory status was assessed one day before admission (A), one day after the end of the hospital 
stay (B), and 8 weeks later (C). Peak expiratory flow rate (PEFR) was measured with a Wright peak flowmeter. Forced vital capacity (FVC), forced expiratory volume in one second $\left(\mathrm{FEV}_{1}\right)$, and mean forced expiratory flow during the middle half of the FVC $\left(\mathrm{FEF}_{25-75}\right)$ were measured using a water-filled spirometer (Jaeger Spiro-Junior) in accordance with standard guidelines. ${ }^{4}$ Functional residual capacity (FRC) was measured by a closed-circuit helium dilution method (Jaeger FRC test). Residual volume (RV) and total lung capacity (TLC) were calculated. The children were trained to perform at maximal effort as judged by reproducibility. Results were expressed as a percentage of the predicted normal values. ${ }^{5}$

During the entire training course each child's PEFR was measured daily at 1100 hours. The best of 3 consecutive measurements was recorded.

Statistical analysis was performed using Student's $t$ test and analysis of variance of regression.

\section{Results}

The children swam and dived for 32 hours, hiked (160 km in a mountainous area) for 64 hours, and did other physical activities for about 32 hours. A gradual increase in performance and endurance was evident. Four of 6 nonswimmers learned to swim.

The training programme was adjusted to the physical capabilities of the majority. Thus it did not always meet satisfactorily each child's individual exercising capacity. Four older children could have coped with a more strenuous work load. The two youngest took part to a reduced extent, yet one of them (a 6-year-old girl, clinical score 37) became repeatedly dyspnoeic and cyanotic while unsuccessfully trying to cough up mobilised secretions, and she resumed her inhalation-physiotherapy

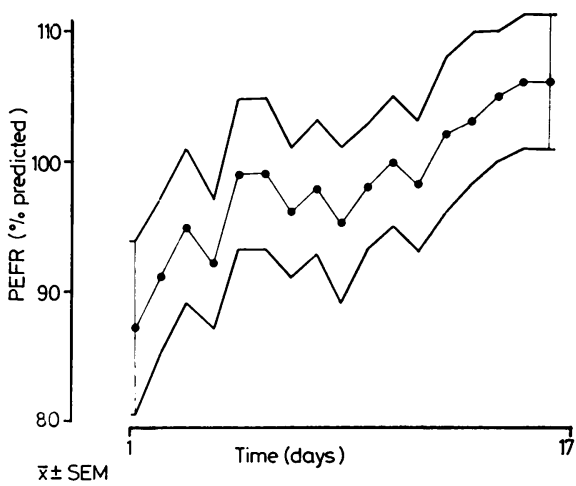

Figure Daily peak flow recordings $(n=10)$.

routine from day 4 onwards. She then slowly increased her exercise tolerance. One other child interrupted her training programme for 5 days because of a mild upper respiratory tract infection.

Pulmonary function data are summarised in the Table. Measurements were obtained from only 10 children. The two youngest patients, including the girl who had required chest physiotherapy, did not co-operate sufficiently to obtain reproducible results. For the whole group FVC, $\mathrm{FEV}_{1}, \mathrm{FEF}_{25-75}$, and PEFR had improved significantly after the course. There was no pronounced change in $\mathrm{FEV}_{1} / \mathrm{FVC}$. Changes, expressed as a percentage of baseline values, did not correlate with these baseline values expressed as a percentage of the predicted normal. $\mathrm{FEV}_{1}$ and $\mathrm{FEF}_{25-75}$ decreased again significantly from B to C. For FVC this decrease just missed significance at the 5\% level. Except for PEFR there was no pronounced difference between $\mathrm{A}$ and $\mathrm{C}$ for any of these parameters.

TLC increased moderately from A to B while RV

Table Pulmonary function tests and statistical comparison $(n=10)$.

\begin{tabular}{|c|c|c|c|c|c|c|}
\hline & $A$ & $A$ versus $B$ & $\boldsymbol{B}$ & $B$ versus $C$ & $C$ & $C$ versus $A$ \\
\hline $\begin{array}{l}\text { FVC } \\
\text { (\% predicted) }\end{array}$ & $88 \cdot 0 \pm 14 \cdot 7$ & $\mathbf{P}<0.05$ & $93 \cdot 8 \pm 13 \cdot 7$ & NS & $88 \cdot 8 \pm 15 \cdot 7$ & NS \\
\hline $\begin{array}{l}\text { FEV } \\
\text { (\% predicted })\end{array}$ & $70 \cdot 6 \pm 21 \cdot 7$ & $P<0.01$ & $79 \cdot 2 \pm 22 \cdot 7$ & $P<0.01$ & $73 \cdot 0 \pm 23 \cdot 3$ & NS \\
\hline $\mathrm{FEV}_{1} / \mathrm{FVC}$ & $67 \cdot 3 \pm 11 \cdot 8$ & NS & $71 \cdot 6 \pm 12 \cdot 3$ & NS & $69 \cdot 1 \pm 13 \cdot 7$ & NS \\
\hline $\begin{array}{l}\text { FEF }_{25-75} \\
\text { (\% predicted) } \\
\text { PEFR }\end{array}$ & $41 \cdot 6 \pm 31 \cdot 5$ & $\mathbf{P}<0.05$ & $52 \cdot 9 \pm 33 \cdot 5$ & $P<0.02$ & $45 \cdot 4 \pm 31 \cdot 5$ & NS \\
\hline TLC & $90 \cdot 9 \pm 16 \cdot 9$ & $P<0.001$ & $109 \cdot 1 \pm 14 \cdot 5$ & NS & $104 \cdot 9 \pm 21 \cdot 8$ & $P<0.02$ \\
\hline $\begin{array}{l}\text { (\% predicted) } \\
\text { RV/TLC }\end{array}$ & $105 \cdot 2 \pm 9 \cdot 5$ & NS & $110 \cdot 6 \pm 8 \cdot 8$ & NS & $109 \cdot 4 \pm 16 \cdot 5$ & NS \\
\hline$(\%)$ & $37 \cdot 7 \pm 12 \cdot 2$ & NS & $34 \cdot 8 \pm 11 \cdot 4$ & NS & $38 \cdot 5 \pm 10 \cdot 9$ & NS \\
\hline
\end{tabular}

$\mathrm{A}=$ assessment 1 day before admission, $\mathrm{B}=$ assessment 1 day after end of hospital stay, $\mathrm{C}=$ assessment 8 weeks later.

Results are mean \pm SD. NS $=$ not significant.

FVC $=$ forced vital capacity, FEV $_{1}=$ forced expiratory volume in one second, FEF $_{25-75}=$ forced expiratory flow during the middle half of the FVC, PEFR = peak expiratory flow rate, $T L C=$ total lung capacity, $R V=$ residual volume. 
and RV/TLC showed a simultaneous tendency to decrease. These volume changes however, did not reach significance.

Daily measurements of PEFR (Figure) demonstrated a steep rise early as well as late in the course. Compared with day 1 , this improvement of PEFR reached significance by day 3 . Frequency of coughing and volume of expectorated sputum, as observed by one of us ( $\mathrm{B} \mathrm{O}$ ), reached a maximum between days 3 and 5, and then decreased gradually to become slight towards the end of the course.

\section{Discussion}

This study demonstrates a beneficial effect of physical exercise on the ventilatory status of children with CF. A similar pattern of improved pulmonary function was recorded after a course of swimming lessons, ${ }^{1}$ but the daily inhalation-physiotherapy routine had then been maintained. Interrupting this routine for the training course did not alter the beneficial response. Training-induced improvement of ventilatory muscle endurance has been noted previously. ${ }^{6}$ A similar effect on ventilatory muscles might, at least in part, be responsible for the positive changes in PEFR. The improvement in the other parameters however, can only be attributed to a favourable effect of airways function. Furthermore, the early steep rise in PEFR in the first 5 days cannot be explained by ventilatory muscle training. It might have been owing to improved clearance of obstructing secretions and seemed to correlate with the maximum degree of coughing and sputum production.

A moderate increase in TLC in the presence of a decreasing RV/TLC indicates recruitment of previously shut-off areas of ventilation. It correlates with the observed increase of FVC. As some areas of trapped gas might not have participated in helium equilibration TLC and RV were most likely underestimated.

The effort-dependent parameter PEFR did not decrease significantly after the end of the course. This, as well as the second steep rise in PEFR, may be owing to ventilatory muscle training. In contrast all other parameters returned to pretraining levels. Hence improvement of airways function seems to depend on the maintenance of physical activity. The value of each activity remains undefined. As shown previously, swimming seems to be an essential part of the programme. ${ }^{1}$

This study shows that regular physical exercise and sports may be a substitute for the inhalationphysiotherapy routine in some CF children. One girl did not tolerate the amount of exercise needed to clear her secretions; hence chest physiotherapy was resumed. Exercise tolerance is severely limited by pulmonary mechanics in some CF patients.? In these advanced stages of the disease any major exertion could be more risky than beneficial. This points out the limitations of group activities and the necessity to adapt any long-term training programme to a child's individual physical capability.

\section{References}

1 Zach M S, Purrer B, Oberwaldner B. Effect of swimming on forced expiration and sputum clearance in cystic fibrosis. Lancet 1981 ; ii: 1201-3.

2 Shwachman H. Cystic fibrosis. In: Kendig E L, Chernick $\mathrm{V}$, eds. Disorders of the respiratory tract in children. Philadelphia: Saunders, 1977: 760-86.

3 Gibson L E, Cooke R E. A test for concentration of electrolytes in sweat in cystic fibrosis of the pancreas utilising pilocarpine by iontophoresis. Pediatrics 1959; 23: 545-9.

4 American Thoracic Society. Snowbird workshop on standardization of spirometry. Statement by the Medical Devices Committee. Am Rev Respir Dis 1979; 119: 831-8.

5 Polgar G, Promadhat V. Pulmonary function testing in children: techniques and standards. Philadelphia: Saunders, 1971.

- Keens T G, Krastins I R B, Wannamaker E M, Levison H, Crozier D N, Bryan A C. Ventilatory muscle endurance training in normal subjects and patients with cystic fibrosis. Am Rev Respir Dis 1977; 116: 853-60.

7 Godfrey S, Mearns M. Pulmonary function and response to exercise in cystic fibrosis. Arch Dis Child 1971; 46: 144-51.

Correspondence to $\operatorname{Dr} \mathbf{M}$ Zach, UniversitätsKinderklinik, Auenbruggerplatz, A-8036 Graz, Austria.

Received 25 January 1982 